\title{
Review of myocardial perfusion imaging in the state of unstable angina
}

\author{
Sudarshana Datta*, Sargun Singh Waila, Aditya Ganti and Arzu Kalayci \\ Cardiovascular Division, Departments of Medicine, Beth Israel Deaconess Medical Center, Harvard Medical School, Boston, Massachusetts, United States
}

\begin{abstract}
Unstable angina may present as transient episodes of myocardial ischemia in different clinical presentations. The use of myocardial perfusion imaging (MPI) in the emergency department (ED) for the accurate diagnosis of unstable angina, in patients with a non-diagnostic ECG seems to be a safe, accurate and potentially costeffective management technique. The use of MPI allows the measurement of myocardial area at risk, infarct size, collateral flow to the infarcted zone and subsequently, myocardial salvage during reperfusion therapy. Therefore, the determination of myocardium at risk for earlier intervention and the reduction in the extent of the affected area following intervention comprises a promising measurement technique for the assessment of acute therapy. This technique has provided significant advances in the field of imaging through efficient triaging of patients having chest pain indicative of unstable angina.
\end{abstract}

\section{Myocardial perfusion imaging}

MPI is a stress imaging modality used commonly in the treatment of coronary artery disease (CAD). Through detection of flow-limiting disease, assessment and quantification of patient risk, MPI is helpful in the evaluation of the presence and severity of CAD. A large number of MPI studies are done with gated single-photon emission computed tomography (SPECT), and more than $50 \%$ are done with vasodilator stress. Gated positron emission tomography (PET), which is nowadays increasingly being used for MPI, provides crucial information such as the severity and the extent of myocardial perfusion abnormalities, mechanical dyssynchrony, myocardial ischemia and left ventricular (LV) function and size. Based on past literature, MPI at rest is a valuable guide to patient management [1].

\section{Unstable angina}

Unstable angina may manifest as transient episodes of myocardial ischemia in various clinical presentations [2]. The pathophysiology of these episodes may include mechanisms such as intracoronary atheromatous plaque rupture, enhanced vasomotor tone, formation of thrombi and platelet aggregation $[3,4]$. The pathophysiology of the unstable angina and its clinical presentation determine the risk of the given patient [5].

\section{Use of SPECT in myocardial imaging}

The use of scintigraphy in the measurement of myocardial risk area with thallium-201 and technetium-99m sestamibi has been verified in several experimental and clinical studies [6-8]. A study by Bilodeau et al. [9] in 1991 demonstrated a high accuracy of Tc-99m SPECT imaging in the diagnosis of coronary artery disease (CAD) and delineation of involved coronary arteries in subjects with spontaneous chest pain.

Even in situations of low coronary blood flow, thallium 201 (TI201) and technetium-99m (Tc-99m) sestamibi have a rapid myocardial uptake relative to blood flow [10]. Due to a considerable amount of radiopharmaceutical redistribution, necessitating immediate imaging after injection, the use of thallium-201 is restricted. As the redistribution amount of technetium-99m has been found to be minimal, it is better suited to evaluation of myocardial area at risk and delineation of zones of hypo perfusion [11]. Within minutes of the injection, it has been seen that the ratio of uptake between the normal and ischemic myocardial areas is determined and remains fixed for hours. Moreover, it is also readily available as a kit preparation [10].

Due to the high-count density of Tc-99m, acquisition of ECG synchronized gated tomograms adds value to angiography results by permitting correlations to be made between coronary anatomy and extent of at-risk myocardium [12].

Gated SPECT has also shown a good correlation with echocardiography for the assessment of both global and regional LV function [13]. A study by Berman et al. [14] has shown that separate acquisition dual-isotope myocardial perfusion SPECT is an excellent technique for the combined evaluation of stress myocardial perfusion and myocardial viability.

\section{Unstable angina and SPECT}

Myocardial perfusion imaging is known to be an important tool in the assessment of angiographic coronary artery disease [7]. In recent years, Tc-99m imaging at rest has been found to have value in the evaluation of perfusion abnormalities during symptomatic stages and asymptomatic or pain free states in unstable angina patients [9]. Optimal management of patients with angina in the emergency department is a major health economic and clinical issue. Majority of these patients may be hospitalized due to deficiencies in the diagnostic accuracy of clinical, historic and electrocardiographic data, despite non-ischemic etiologies for their chest pain. Although age, gender and known coronary disease have some discriminating value, diagnostic

${ }^{*}$ Correspondence to: Sudarshana Datta, MD, Baim Institute for Clinical Research 930 Commonwealth Ave Boston, MA 02215, United States, Tel: + (617) 800-6637; E-mail: sdatta2@bidmc.harvard.edu

Received: April 25, 2018; Accepted: May 10, 2018; Published: May 18, 2018 
uncertainty arises due to overlap in clinical presentation in patients with and without cardiac ischemia [15-17]. The additional cost of evaluation of this patient group is four billion dollars annually [18]. It has also been shown that $4-8 \%$ of MI patients are inappropriately discharged from emergency departments, leading to deleterious consequences $[19,20]$.

The use of myocardial perfusion imaging with Tc-99m sestamibi in ED patients with angina and a no diagnostic ECG seems to be a safe, accurate and potentially cost-effective management technique. If lowrisk patients with chest pain with a normal scan become candidates for outpatient cardiac evaluation, SPECT can reduce the cost of managing ED patients [21].

The agent Tc-99m has provided significant advances in the field of imaging by allowing patient triaging of symptomatic patients (chest pain suggestive of unstable angina). The use of Tc- $99 \mathrm{~m}$ sestamibi perfusion scan allows the measurement of myocardial area at risk, infarct size, collateral flow to the infarcted zone and subsequently, myocardial salvage during reperfusion therapy. [22]

Patients having a normal SPECT perfusion scan also have excellent prognosis. A very low risk of adverse events both in the hospital and at 90 days of follow up has been shown in ED patients with typical angina with a non-diagnostic or normal electrocardiogram (ECG) with a normal initial SPECT perfusion scan (at the time of chest pain) [23]. Injection of Tc-99m can be given at a selected time while they are symptomatic due to minimal redistribution and scintigraphic acquisition may be performed 6-8 hours later after clinical stabilization, thereby preventing any delay in treatment initiation [12,24]. Sestamibi has been shown to have a higher sensitivity and specificity for the detection of acute ischemia as compared to clinical findings and ECG changes $[9,25,26]$. Varetto et al. [26] showed the SPECT imaging in the ED had a sensitivity of $100 \%$ for detection of ACS in symptomatic patients with non-diagnostic ECGs, with a specificity of $92 \%$ for $\mathrm{CAD}$ detection. Identification is important because there has been a dramatic increase in the numbers of patients with unstable angina over the years, approaching numbers of admitted MI patients [19,27]. A study by Gregoire et al. [10] showed that a negative perfusion scan in a symptomatic patient could rule out significant coronary stenosis with a high level of confidence, while a positive scan could predict its presence with high accuracy. Additionally, a reduction in the size of a perfusion defect between images obtained in the pain and pain- free states could aid in the diagnosis of myocardial ischemia.

Early detection and aggressive treatment of unstable angina can help in the reduction of high, short term cardiovascular morbidity and mortality. As elevated cardiac markers are not detectable in patients experiencing ischemia without myocardial necrosis, positive early perfusion imaging permits rapid treatment initiation that helps prevent progression to MI. Additionally, early stress testing can be performed on patients with negative perfusion imaging, thereby reducing hospital resource costs [24].

Although patients may be pain free at the time of injection, it is clear that positive early perfusion imaging accurately identifies patients with ongoing ischemia or infarction. $[9,25,26]$ SPECT imaging has higher sensitivity for the diagnosis of small infarcts as compared to planar imaging $[28,29]$. The demonstrated benefit in the measurement of final infarct size and myocardial salvage showcases the fact that the use of myocardial perfusion imaging with SPECT provides a superior, new, powerful tool to ensure treatment efficacy in unstable angina. [30]

In conclusion, it is clear from all the previous studies that SPECT is a promising technique for the detection of unstable angina in the ED. However, only further research and randomized trials are required to throw further light on its efficacy as compared to the existing diagnostic modalities. Although past literature supports this idea, only greater exploration in the field of myocardial scintigraphy can determine whether this can be incorporated as a standard diagnostic modality in the diagnosis of unstable angina in the emergency setting.

\section{References}

1. Ben-Haim S, Murthy VL, Breault C, Allie R, Sitek A, et al. (2013) Quantification of myocardial perfusion reserve using dynamic SPECT imaging in humans: a feasibility study. J Nucl Med 54: 873-879. [Crossref]

2. van Miltenburg-van Zijl AJ, Simoons ML, Veerhoek RJ, Bossuyt PM (1995) Incidence and follow-up of Braunwald subgroups in unstable angina pectoris. $J$ Am Coll Cardiol 25: 1286-1292. [Crossref]

3. Forrester JS, Litvack F, Grundfest W, Hickey A (1987) A perspective of coronary disease seen through the arteries of living man. Circulation 75: 505-513. [Crossref]

4. Théroux P (1987) A pathophysiologic basis for the clinical classification and management of unstable angina. Circulation 75: V103-109. [Crossref]

5. Ouyang P, Brinker JA, Mellits ED, Weisfeldt ML, Gerstenblith G (1984) Variables predictive of successful medical therapy in patients with unstable angina: selection by multivariate analysis from clinical, electrocardiographic, and angiographic evaluations. Circulation 70: 367-376

6. De Coster PM, Wijns W, Cauwe F, Robert A, Beckers C et al. (1990) Area-atrisk determination by technetium-99m-hexakis-2-methoxyisobutyl isonitrile in experimental reperfused myocardial infarction. Circulation 82: 2152-2162. [Crossref]

7. Huber KC, Bresnahan JF, Bresnahan DR, Pellikka PA, Behrenbeck T, et al. (1992) Measurement of myocardium at risk by technetium- $99 \mathrm{~m}$ sestamibi: correlation with coronary angiography. J Am Coll Cardiol 19: 67-73. [Crossref]

8. Feiring AJ, Johnson MR, Kioschos JM, Kirchner PT, Marcus ML, et al. (1987) The importance of the determination of the myocardial area at risk in the evaluation of the outcome of acute myocardial infarction in patients. Circulation 75: 980-987. [Crossref]

9. Bilodeau L, Théroux P, Grégoire J, Gagnon D, Arsenault A (1991) Technetium-99m sestamibi tomography in patients with spontaneous chest pain: correlations with clinical, electrocardiographic and angiographic findings. J Am Coll Cardiol 18: 1684 1691. [Crossref]

10. Grégoire J, Théroux P (1990) Detection and assessment of unstable angina using myocardial perfusion imaging: comparison between technetium- $99 \mathrm{~m}$ sestamibi SPECT and 12-lead electrocardiogram. Am J Cardiol 66: 42E-46E. [Crossref]

11. Haronian HL, Remetz MS, Sinusas AJ, Baron JM, Miller HI, et al. (1993) Myocardial risk area defined by technetium- $99 \mathrm{~m}$ sestamibi imaging during percutaneous transluminal coronary angioplasty: comparison with coronary angiography. J Am Coll Cardiol 22: 1033-1043. [Crossref]

12. Emre A, Ersek B, Gursuer M, Aksoy M, Siber T, et al. (2000) Angiographic and scintigraphic (perfusion and electrocardiogram-gated SPECT) correlates of clinical presentation in unstable angina. Clin Cardiol 23: 495-500. [Crossref]

13. Chua T, Kiat H, Germano G, Maurer G, van Train K, et al. (1994) Gated technetium$99 \mathrm{~m}$ sestamibi for simultaneous assessment of stress myocardial perfusion, postexercise regional ventricular function and myocardial viability. Correlation with echocardiography and rest thallium-201 scintigraphy. J Am Coll Cardiol 23:1107-1114. [Crossref]

14. Berman DS, Kiat H, Friedman JD, Wang FP, van Train K, et al. (1993) Separate acquisition rest thallium-201/stress technetium-99m sestamibi dual-isotope myocardial perfusion single-photon emission computed tomography: a clinical validation study. $J$ Am Coll Cardiol 22: 1455-1464. [Crossref]

15. Pozen MW, D’Agostino RB, Selker HP, Sytkowski PA, Hood WB (1984) A predictive instrument to improve coronary-care-unit admission practices in acute ischemic heart disease. A prospective multicenter clinical trial. N Engl J Med 310: 1273-1278. [Crossref]

16. Lee TH, Cook EF, Weisberg M, Sargent RK, Wilson C (1985) Acute chest pain in the emergency room. Identification and examination of low-risk patients. Arch Intern Med 145: 65-69. [Crossref]

17. Aase O, Jonsbu J, Liestøl K, Rollag A, Erikssen J (1993) Decision support by computer analysis of selected case history variables in the emergency room among patients with acute chest pain. Eur Heart $J$ 14: 433-440

18. Fineberg HV, Scadden D, Goldman L (1984) Care of patients with a low probability of acute myocardial infarction. Cost effectiveness of alternatives to coronary-care-unit admission. N Engl J Med 310: 1301-1307. [Crossref] 
19. Lee TH, Rouan GW, Weisberg MC, Brand DA, Acampora D (1987) Clinical characteristics and natural history of patients with acute myocardial infarction sent home from the emergency room. Am J Cardiol 60: 219-224. [Crossref]

20. McCarthy BD, Beshansky JR, D'Agostino RB, Selker HP (1993) Missed diagnoses of acute myocardial infarction in the emergency department: results from a multicenter study. Ann Emerg Med 22: 579-582. [Crossref]

21. Radensky PW, Hilton TC, Fulmer H, McLaughlin BA, Stowers SA (1997) Potentia cost effectiveness of initial myocardial perfusion imaging for assessment of emergency department patients with chest pain. Am J Cardiol 79: 595-599. [Crossref]

22. Christian TF, Gibbons RJ (1994) Myocardial perfusion imaging in myocardia infarction and unstable angina. Cardiol Clin 2: 247-260. [Crossref]

23. Hilton TC, Fulmer H, Abuan T, Thompson RC, Stowers SA (1996) Ninety-day followup of patients in the emergency department with chest pain who undergo initial singlephoton emission computed tomographic perfusion scintigraphy with technetium 99m-labeled sestamibi. J Nucl Cardiol 3: 308-311. [Crossref]

24. Kontos MC, Jesse RL, Schmidt KL, Ornato JP, Tatum JL (1997) Value of acute rest sestamibi perfusion imaging for evaluation of patients admitted to the emergency department with chest pain. J Am Coll Cardiol 30: 976-982. [Crossref]
25. Hilton TC, Thompson RC, Williams HJ, Saylors R, Fulmer H (1994) Technetium-99m sestamibi myocardial perfusion imaging in the emergency room evaluation of chest pain. J Am Coll Cardiol 23: 1016-1022. [Crossref]

26. Varetto T, Cantalupi D, Altieri A, Orlandi C (1993) Emergency room technetium$99 \mathrm{~m}$ sestamibi imaging to rule out acute myocardial ischemic events in patients with nondiagnostic electrocardiograms. J Am Coll Cardiol 22: 1804-1808. [Crossref]

27. Selker HP, Griffith JL, D’Agostino RB (1991) A tool for judging coronary care unit admission appropriateness, valid for both real-time and retrospective use. A timeinsensitive predictive instrument (TIPI) for acute cardiac ischemia: a multicenter study. Med Care 29: 610-627. [Crossref]

28. Tamaki S, Kambara H, Kadota K, Suzuki Y, Nohara R, et al. (1984) Improved detection of myocardial infarction by emission computed tomography with thallium-201. Relation to infarct size. B Heart J 52: 621-627. [Crossref]

29. Verani MS, Jeroudi MO, Mahmarian JJ, Boyce TM, Borges-Neto S, et al. (1988) Quantification of myocardial infarction during coronary occlusion and myocardial salvage after reperfusion using cardiac imaging with technetium-99m hexakis 2-methoxyisobutyl isonitrile. J Am Coll Cardiol 12: 1573-1581. [Crossref]

30. Gibbons RJ (1991) Technetium 99m sestamibi in the assessment of acute myocardial infarction. Semin Nucl Med 3: 213-222. [Crossref]

Copyright: (2018 Datta S. This is an open-access article distributed under the terms of the Creative Commons Attribution License, which permits unrestricted use, distribution, and reproduction in any medium, provided the original author and source are credited. 